\title{
UK energy forecast: Sussex study sheds doubt on official figures
}

PRIMARY energy consumption in the UK at the end of the century may be markedly below recent estimates made by Department of Energy officials, according to a report published this week by the Science Policy Research Unit (SPRU) at Sussex University. The difference may lie in a hidden assumption in the Department's calculations (published in Energy Commission Papers 1 and 5) that electricity consumption will remain high at the end of the century, says the Sussex report.

SPRU pays tribute in the report to the "big advance in government thinking" marked by Energy Commission Paper 1, and agrees with the estimates of the DOE (Department of Energy) for 'high' and 'low' growth energy use in the year 2,000. However, SPRU estimates a $25 \%$ lower primary fuel consumption for the same low final use as the DOE. "The difference cannot be explained unless a considerably higher level of electricity consumption (and hence conversion losses) was implicitly assumed in Energy Commission Paper 1" says the report.

Electricity is an inefficient way of using primary fossil fuel, involving a conversion efficiency at a modern power station of only $35 \%$. So it tends to be more expensive per useable therm than primary fuel.

Primary energy demand in the UK in the year 2000: some conflicting forecasts. Left. the 1976 projections of the Department of Energy (DOE) Advisory Committee on Research and Development (ACORD): 1, trends continued; 2, low growth; 3, limit on nuclear; 4, high energy costs; 5, price transition; 6 . self-sufficienc' $y$; 7. high growth. Centre, the most recent DOE forecasts: 1. Energy Policy Review (1977): 2, Energy Commission Paper I (1977). Right, the SPRU results: 1, high economic growth. low conservation; 2. high economic growth, high conservation: 3, low economic growth, high conservation.

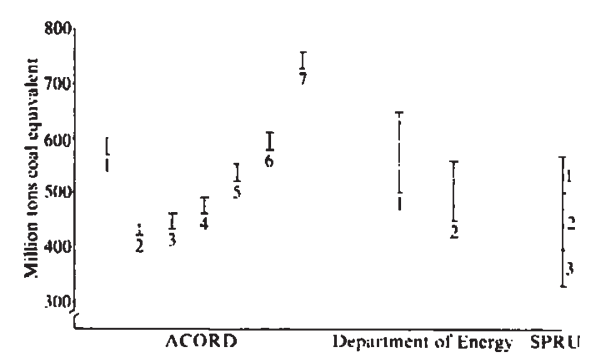

Thus it loses ground in market competition with primary fuel--such as North Sea Gas. UK domestic consumption of electricity, for example was about equal to gas consumption in 1960 ; but by 1976 it was only half, gas having won the greater part of the shrinking domestic solid fuel market. By the end of the century, gas is bound to substitute for non-essential uses of electricity (principally heating) unless government pricing policy artificially prevents it.

The DOE and SPRU appear to agree that the reserves of North Sea Gas and the present contracts with the suppliers all but guarantee a flow of gas of some 6000 million cubic feet a day at the year 2000 ; so the contradiction must lie in the degree to which gas will substitute for electricity. Drs John Surrey and John Chesshire, authors of the SPRU report, argue that if there were to be a low (but quite conventional) economic growth in the UK of 1 to $2 \%$ a year, the total energy market would be smaller and the competition fiercer. In this way they reach the conclusion that the bulk of nonessential electricity use would be substituted by gas by the end of the century. There would continue to be substitution even in the high growth (3 to 4), case but it would be less marked.

A relatively low electricity usage at the end of the century is significant for two reasons: first it has a dramatic effect on primary fuel usage through the inefficiency of conventional power stations (which multiplies the effect by roughly three); and second, it affects policy for the near-future commissioning of new power stations. For example, the Department of Energy main forecast allows for $40 \mathrm{GW}$ of installed nuclear capacity by the year 2000 , compared to about $4 \mathrm{GW}$ today. The $25 \%$ SPRU variation in primary demand from the DOE 'low' estimate is the electrical equivalent of some 55 GW: sufficient to make a considerable difference in ordering policy.

Drs Surrey and Chesshire were initially very impressed with the DOE forecast contained in Energy Commission Paper 1. The first draft of their study was only five days old when the Energy Commission Paper came out. "We nearly fell out of our chairs" said Dr Surrey this week. "We discussed whether we should bury what we had done. But more and more the very shadowy lower case in the Energy

\section{Sorry, for copyright reasons some images on this page may not be available online}

Drilling for North Sea Gas: has the Department of Energy underestimated this fuel's competitiveness?

Commission Paper began to worry us". In the report Drs Surrey and Chesshire describe the DOE 'reference' case and then write of the "less well-documented, almost parenthetical 'lower' case' which is "not sufficiently spelled out".

The 'low' primary consumption in the SPRU forecasts works out at 335 million tons of coal equivalent a year, compared to 450 in the DOE forecasta difference of 115 mtce. A small part of the difference can be explained by SPRU's lower estimate of the nonenergy use of primary fuels, but some 80 to 100 mtce remains to be accounted for. It was here that the SPRU forecasters concluded that the DOE must be making an assumption of high electricity use. "We think such an assumption to be unrealistic" says the report "because under low economic growth, although electricity-specific demands would doubtless continue to expand, there would be no significant substitution by electricity in competitive uses because of the availability of natural gas".

The SPRU report claims to be conservative. "Views are bound to differ about the plausibility of alternative estimates" write the authors. "We put ours forward as a contribution to the debate about future policy options. Like Energy Commission Paper 1, our estimates are based on a fairly 'conventional' view of the future and should not be seen as an extreme low growth' scenario involving radical changes in lifestyle".

Robert Walgate 